\title{
PCDHB15 as a potential tumor suppressor and epigenetic biomarker for breast cancer
}

\author{
CHING-CHUNG CHIANG ${ }^{1 *}$, GUAN-LING LIN ${ }^{2-4^{*}}$, SHU-YI YANG $^{2,5^{*}}$, CHI-WEN TU ${ }^{1}$, WEN-LONG HUANG ${ }^{5}$, \\ CHUN-FENG WEI ${ }^{1}$, FENG-CHI WANG ${ }^{2,3}$, PIN-JU LIN ${ }^{2,3}$, WAN-HONG HUANG ${ }^{2,3}$, YU-MING CHUANG ${ }^{2,3}$, \\ YU-TING LEE ${ }^{2,6}$, CHIA-CHOU YEH ${ }^{5,7}$, MICHAEL W.Y. CHAN ${ }^{2-4}$ and YU-CHEN HSU ${ }^{1}$ \\ ${ }^{1}$ Department of Surgery, Ditmanson Medical Foundation Chiayi Christian Hospital, Chiayi 60002; \\ ${ }^{2}$ Department of Biomedical Sciences, National Chung Cheng University; ${ }^{3}$ Epigenomics and Human Disease Research Center; \\ ${ }^{4}$ Center for Innovative Research on Aging Society, National Chung Cheng University, Chiayi 62101; \\ ${ }^{5}$ Department of Chinese Medicine, Dalin Tzuchi Hospital, The Buddhist Tzuchi Medical Foundation, Chiayi 62247; \\ ${ }^{6}$ Division of Hematology and Oncology, Department of Medicine, Ditmanson Medical Foundation Chiayi Christian Hospital, \\ Chiayi 60002; ${ }^{7}$ School of Post-Baccalaureate Chinese Medicine, Tzu Chi University, Hualien 97004, Taiwan, R.O.C.
}

Received August 17, 2021; Accepted January 7, 2022

DOI: $10.3892 / \mathrm{ol} .2022 .13237$

\begin{abstract}
Breast cancer is among the most frequently diagnosed cancer types and the leading cause of cancer-related death in women. The mortality rate of patients with breast cancer is currently increasing, perhaps due to a lack of early screening tools. In the present study, using The Cancer Genome Atlas (TCGA) breast cancer dataset $(n=883)$, it was determined that methylation of the protocadherin $\beta 15$ (PCDHB15) promoter was higher in breast cancer samples than that in normal tissues. A negative association between promoter methylation and expression of $P C D H B 15$ was observed in the TCGA dataset and breast cancer cell lines. In TCGA cohort, lower PCDHB15 expression was associated with shorter relapse-free survival times. Treatment with the DNA methyltransferase inhibitor restored $\mathrm{PCDHB15}$ expression in a breast cancer cell line; however, overexpression of $P C D H B 15$ was shown to suppress colony formation. PCDHB15 methylation detected in circulating cell-free DNA (cfDNA) isolated from serum samples was higher in patients
\end{abstract}

Correspondence to: $\mathrm{Dr}$ Michael W.Y. Chan, Department of Biomedical Sciences, National Chung Cheng University, 168 University Road, Minxiong Township, Chiayi 62101, Taiwan, R.O.C.

E-mail: biowyc@ccu.edu.tw

Dr Yu-Chen Hsu, Department of Surgery, Ditmanson Medical Foundation Chiayi Christian Hospital, 539 Zhongxiao Road, Chiayi 60002, Taiwan, R.O.C.

E-mail: seetowhat@gmail.com

*Contributed equally

Key words: protocadherin $\beta 15$, DNA methylation, cell-free DNA, breast cancer, biomarker with breast cancer (40.8\%) compared with that in patients with benign tumors (22.4\%). PCDHB15 methylation was not correlated with any clinical parameters. Taken together, $P C D H B 15$ is a potential tumor suppressor in cases of breast cancer, which can be epigenetically silenced via promoter methylation. $P C D H B 15$ methylation using cfDNA is a novel minimally invasive epigenetic biomarker for the diagnosis and prognosis of breast cancer.

\section{Introduction}

Globally, breast cancer is the second most common cancer and the most common cancer in women. In Taiwan, the age-standardized incidence rate (ASIR) of female breast cancer was 70.7 per 100,000 individuals in 2014, and the ASIR gradually increased at a rate of 3.5 per 100,000 person-years $(1,2)$. The age of breast cancer onset is currently 10 years younger than that in Western countries (3). Thus, early detection and early treatment are important objectives for patients with breast cancer (4). At present, diagnosis and disease monitoring primarily involve tissue biopsy and imaging. Tissue biopsy is an invasive method limited to specific regions (5). Mammography is the gold standard for breast cancer detection due to its high sensitivity and specificity; however, numerous women tend to avoid this due the exposure to radiation (6). A novel minimally invasive biomarker for breast cancer is needed.

Liquid biopsy from bodily fluid, such as circulating cell-free DNA (cfDNA), circulating tumor cells and exosomes, is minimally invasive and has proven both convenient and effective in cancer diagnosis $(7,8)$. The quantity of cfDNA in the blood can be used to characterize tumorigenesis, inflammatory disease and stroke (9). The Epi-proColon blood test for circulating methylated DNA has been approved for the detection of colorectal cancer $(10,11)$. It has been revealed that genomic alterations, such as human epidermal growth factor receptor 2 (HER2) amplification, can serve as a predictive 
biomarker for breast cancer (12); however, the identification of valid diagnostic biomarkers for breast cancer from liquid biopsy is needed.

DNA methylation, occurring at $\mathrm{CpG}$ dinucleotides, is a hallmark of cancer (13). As this epigenetic change occurs early in tumorigenesis, it can be used as a biomarker for early detection, disease prognosis and monitoring (14). Several studies have reported the presence of methylated DNA in serum samples from patients with cancer of the gastrointestinal tract, lung, head and neck, liver and breast (15-17). In cases of breast cancer, DNA methylation signature is related to the clinicopathological characteristics of the tumor, such as tumor stage and grade $(18,19)$. It is possible that DNA methylation-mediated epigenetic silencing of tumor suppressors could affect the progression and prognosis of breast cancer (20-22). One previous study demonstrated that hypermethylation of seven biomarkers, including protocadherin $\beta 15$ (PCDHB15), could differentiate patients with breast cancer into the high- and low-risk groups (23).

$P C D H B 15$ is a member of the cadherin superfamily and calcium-dependent cell-cell adhesion molecules, which encodes for PCDHB15 protein in humans $(24,25)$. Several cell adhesion molecules, such as CDH1 (also known as E-cadherin), act as epithelial-mesenchymal transition suppressors (26). In this regard, the epigenetic silencing of $\mathrm{CDH} 1$ has frequently been observed in cases of human cancer, including breast cancer (27-29). Nonetheless, the role played by the epigenetic silencing of $P C D H B 15$ in cases of breast cancer remains unclear. In the present study, $P C D H B 15$ was identified as a potential tumor suppressor gene in breast cancer, based on the observation that $P C D H B 15$ expression is positively correlated with the likelihood of relapse-free survival. The detection of $P C D H B 15$ methylation in serum samples of patients with breast cancer could be a novel minimally invasive biomarker for the diagnosis and prognosis of breast cancer.

\section{Materials and methods}

Cell culture. MCF7 and MDA-MB-231 human breast cancer cell lines were maintained in DMEM (Gibco; Thermo Fisher Scientific, Inc.), supplemented with $10 \%$ fetal bovine serum (FBS; Invitrogen; Thermo Fisher Scientific, Inc.) and $50 \mathrm{U} / \mathrm{ml}$ penicillin/streptomycin (Invitrogen; Thermo Fisher Scientific, Inc.). The cells were incubated under $5 \% \mathrm{CO}_{2}$ at $37^{\circ} \mathrm{C}$. DNA demethylation involved treating the cells with $0.1 \mu \mathrm{M}$ DNA methyltransferase (DNMT) inhibitor 5'-aza-2'-deoxycytidine, (5aza; Merck KGaA) or DMSO (as control) at $37^{\circ} \mathrm{C}$ for $72 \mathrm{~h}$. Culture media and drugs were replenished every $24 \mathrm{~h}$. Following treatment, the cells were harvested for RNA analysis.

Patient samples. All patient samples were collected from the Biobank of the Ditmanson Medical Foundation Chiayi Christian Hospital, Chiayi, Taiwan (Table I). The cancer group (age range, 30-78 years) was comprised of patients with confirmed breast cancer, whereas the control group (age range, 20-53 years) was comprised of patients diagnosed with benign tumors. The inclusion criteria were patients $>20$ years old and who were undergoing biopsy or mastectomy; exclusion criteria were patients who could not undergo any surgery or blood sampling. Serum samples obtained from patients with breast cancer $(n=49)$ and patients with benign tumors $(n=49)$ were used for quantitative methylation-specific PCR (qMSP) analysis. Briefly, blood samples were drawn into a $10-\mathrm{ml} \mathrm{K}_{2}$-EDTA blood tube (BD Biosciences) and centrifuged at $1,358 \mathrm{x} \mathrm{g}$ at room temperature for $10 \mathrm{~min}$, whereupon the serum was collected and stored at $-80^{\circ} \mathrm{C}$. The present study was approved (approval no. IRB2019006 on 2019/3/5) by the Institutional Review Board of the Ditmanson Medical Foundation Chiayi Christian Hospital (Chiayi, Taiwan) and performed in strict accordance with approved guidelines. Written informed consent was obtained from all participants.

Plasmid transfection and colony formation. The full-length human $P C D H B 15$ expression plasmid was a gift from Professor Jun Yu (Chinese University of Hong Kong, Hong Kong). $P C D H B 15$-expressing or empty vectors $(5 \mu \mathrm{g}$; pCMV6-XL5) were transfected into MDA-MB-231 cells (a triple-negative breast cancer cell line with lower expression of PCDHB15) using TransIT-LT1 Transfection Reagent (Mirus Bio LLC) in accordance with the manufacturer's protocol. After $72 \mathrm{~h}$ of incubation at $37^{\circ} \mathrm{C}$, the transfection reagents were removed and replaced with fresh medium. Transfected cells were cultured in fresh medium at $37^{\circ} \mathrm{C}$ prior to further experiments.

For the colony-formation analysis, a total of $1 \times 10^{4}$ transfected cells per well were seeded in three $6-\mathrm{cm}$ dishes with complete culture medium. Cells were cultured in fresh culture medium at $37^{\circ} \mathrm{C}$ for 5-7 days, and the culture medium was replaced at intervals of 3 days. Surviving colonies were stained with $0.4 \%$ crystal violet (solubilized in $50 \%$ methanol) at room temperature for $30 \mathrm{~min}$. The number of colonies (as defined by the size of the colonies $>5 \mathrm{pixel}^{2}$ ) was then calculated by using ImageJ $1.53 \mathrm{e}$ software (National Institutes of Health).

RNA extraction and reverse transcription-quantitative PCR. Total RNA was extracted from the MCF7 and MDA-MB-231 cells using TRIzol ${ }^{\circledR}$ (Invitrogen; Thermo Fisher Scientific, Inc.) in accordance with the manufacturer's protocol. Briefly, $1 \mu \mathrm{g}$ of total RNA was treated with DNase I (Amplification grade; Invitrogen; Thermo Fisher Scientific, Inc.), before it underwent reverse transcription. First-strand cDNA synthesis was performed using MMLV Reverse Transcriptase (Epicentre; Illumina, Inc.) with oligo dT primers. Briefly, RNA was denatured and the oligo dT primers were annealed at $65^{\circ} \mathrm{C}$ for $2 \mathrm{~min}$, then chilled on ice for $1 \mathrm{~min}$. The mixture was gently mixed with dNTP, DTT, RNase inhibitor, X10 RT reaction buffer and MMLV Reverse Transcriptase. The final 20- $\mu 1$ mixture was incubated at $37^{\circ} \mathrm{C}$ for $60 \mathrm{~min}$ followed by $85^{\circ} \mathrm{C}$ for 5 min. qPCR was performed using an ABI Step-One real-time PCR system (Applied Biosystems; Thermo Fisher Scientific, Inc.) with specific primers and Power SYBR Green Master Mix (Applied Biosystems; Thermo Fisher Scientific, Inc.). The thermocycling conditions were as follows: Initial denaturation at $95^{\circ} \mathrm{C}$ for $10 \mathrm{~min}$, followed by 40 cycles of $95^{\circ} \mathrm{C}$ for $15 \mathrm{sec}, 60^{\circ} \mathrm{C}$ for $30 \mathrm{sec}$ and $72^{\circ} \mathrm{C}$ for $30 \mathrm{sec}$. The primer sequences were as follows: $P C D H B 15$ forward, $5^{\prime}$-agc ctttcaggagaaattcgactaat-3' and reverse, 5'-gcaccttaacagaga cagagcatttt-3'; and GAPDH forward, 5'-cccttcattgacctcaacta cat-3' and reverse, 5'-cgctcctggaagatggtga-3'. Relative gene expression was calculated by comparing the quantification 
Table I. Summary of cliniopathological data of plasma samples.

\begin{tabular}{lcc}
\hline & \multicolumn{2}{c}{ Plasma samples } \\
\cline { 2 - 2 } Clinicopathological & Cancer $(\mathrm{n}=49)$ & Benign $(\mathrm{n}=49)$ \\
\hline Age, years & $55.12 \pm 10.59^{\mathrm{a}}$ & $34.96 \pm 9.92$ \\
Histological grade & \\
Low grade & 37 \\
High grade & 8 \\
Unknown & \\
Estrogen receptor & 18 \\
- & 30 \\
+ & 1 \\
Unknown & \\
Progesterone receptor & 20 \\
- & 28 \\
+ & 1 \\
Unknown & \\
Human epidermal growth & \\
factor receptor 2 & 19 \\
- & \\
+ & \\
\hline
\end{tabular}

${ }^{\mathrm{a}}$ Mean $\pm \mathrm{SD}$; ${ }^{\mathrm{b}}$ Grading: Low grade, $\mathrm{G} 1$; high grade, $\mathrm{G} 2-3$.

cycle $(\mathrm{Cq})$ value of $P C D H B 15$ gene against the $\mathrm{Cq}$ value of $G A P D H$ in a given sample (i.e., $2^{-\Delta \Delta \mathrm{Cq}}$ ) (30).

Extraction and bisulphite conversion of DNA. DNA was extracted from serum samples using the QIAamp Circulating Nucleic Acid kit (Qiagen $\mathrm{GmbH}$ ) in accordance with the manufacturer's protocol. Extracted DNA was bisulphite-modified using the EZ DNA methylation kit (ZYMO Research Corp.) in accordance with the manufacturer's protocol, as previously described (31).

MSP and qMSP. PCDHB15 methylation in serum samples was detected by subjecting the bisulphite-modified DNA to MSP and qMSP, as previously described (32). Briefly, $4 \mu 1$ bisulphite-converted DNA was subjected to MSP within the specific promoter $P C D H B 15$ region. The thermocycling conditions were as follows: Initial denaturation at $95^{\circ} \mathrm{C}$ for $10 \mathrm{~min}$, followed by 40 cycles of $95^{\circ} \mathrm{C}$ for $15 \mathrm{sec}, 60^{\circ} \mathrm{C}$ for $30 \mathrm{sec}$ and $72^{\circ} \mathrm{C}$ for $30 \mathrm{sec}$. The PCR products were analyzed by electrophoresis in $10 \%$ polyacrylamide gel and subsequent the gel was stained with ethidium bromide. For qMSP analysis, $4 \mu \mathrm{l}$ bisulphite-converted DNA was subjected to qMSP within the specific promoter $P C D H B 15$ region using an ABI Step One real time PCR system (Applied Biosystems; Thermo Fisher Scientific, Inc.) and Power SYBR Green Master Mix. The thermocycling conditions were as follows: Initial denaturation at $95^{\circ} \mathrm{C}$ for $10 \mathrm{~min}$, followed by 40 cycles of $95^{\circ} \mathrm{C}$ for $15 \mathrm{sec}$, $60^{\circ} \mathrm{C}$ for $30 \mathrm{sec}$ and $72^{\circ} \mathrm{C}$ for $30 \mathrm{sec}$. The primer sequences for PCDHB15 were as follows: Forward, 5'-acgtttttttaaggaatcg-3' and reverse, 5'-acgaaccaatatctccga-3' (130 bp). The presence of cfDNA in serum samples was detected via collagen type II $\alpha 1$ chain (COL2A1) MSP using the forward primer 5'-tctaacaattat aaactccaaccaccaa-3' and the reverse primer 5'-gggaagatggga tagaagggaatat-3'. The quantity of methylated DNA was determined in terms of $\mathrm{Cq}$ value against a standard curve generated using an in vitro methylated DNA-MSP cloned fragment, as previously described (33).

TCGA data analysis. The Cancer Genome Atlas (TCGA) breast cancer (BRCA) Methylation $450 \mathrm{~K}$ dataset was downloaded from UCSC Xena (http://xena.ucsc.edu). The methylation level of $\mathrm{CpG}$ sites in $\mathrm{PCDHB} 15$ between solid normal tissues and primary tumor tissues were compared and analyzed. Associations between the expression and methylation (cg17023770) of PCDHB15 were analyzed.

Statistical analysis. All statistical analysis was performed using GraphPad Prism Version 5.0 software packages for Windows (GraphPad Software, Inc.). Differences between two groups were analyzed using an unpaired Student's t-test or the Mann-Whitney U test. Pearson's correlation analysis was used to analyze correlation between gene expression, methylation status of a gene or protein expression. Locoregional relapse-free survival was assessed by Kaplan-Meier analysis, and differences between groups were estimated by the log-rank test. $\mathrm{P}<0.05$ was considered to indicate a statistically significant difference.

\section{Results}

PCDHB15 is hypermethylated in breast tumor samples compared with that in normal samples. Breast cancer data from TCGA were first used to analyze DNA methylation profiles for $P C D H B 15$. The present study included 785 primary tumors and 98 solid tissue normal samples. The methylation of PCDHB15 was higher in tumor samples than that in normal solid tissue $(\mathrm{P}<0.001$; Fig. $1 \mathrm{~A}$ and $\mathrm{B})$. As expected, a negative association between the methylation of a particular CG site (cg 17023770) in the promoter region and the expression of PCDHB15 was observed in this TCGA cohort (Fig. 1C; $r=-0.2$, $\mathrm{P}<0.0001)$. Kaplan-Meier Plotter (34) revealed that patients with lower $P C D H B 15$ expression were associated with shorter relapse-free survival times (Fig. 1D; HR, 0.74; $\mathrm{P}=0.00011$ ), but not at all with overall survival times (data not shown).

The association between promoter methylation and the expression of $P C D H B 15$ in breast cancer cell lines was then investigated. It was determined that the expression of PCDHB15 was downregulated in MDA-MB-231 cells compared with that in MCF7 cells (Fig. 1E). Concomitantly, bisulphite pyrosequencing revealed that promoter methylation was higher in MDA-MB-231 cells than that in MCF7 cells at $\mathrm{CpG}$ sites located in the upstream promoter region of PCDHB15 (Fig. 1F). Notably, the expression of PCDHB15 in MDA-MB-231 cells was restored upon treatment using DNMT inhibitor (0.1 $\mu \mathrm{M}$ 5aza; Fig. $1 \mathrm{G})$.

To examine the function of $P C D H B 15, P C D H B 15$ was overexpressed in MDA-MB-231 breast cancer cells, showing a lower $P C D H B 15$ expression, as compared with MCF7 cells. The induced overexpression of $P C D H B 15$ 
A

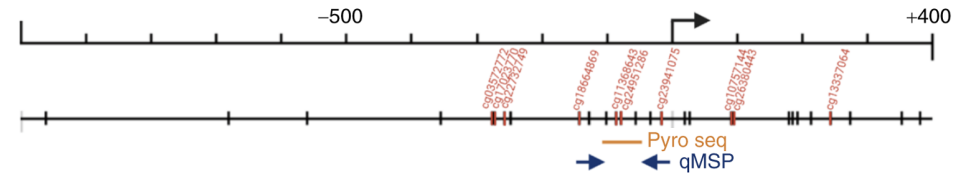

B

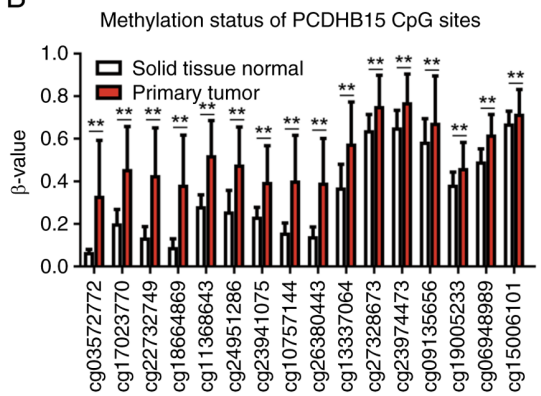

D

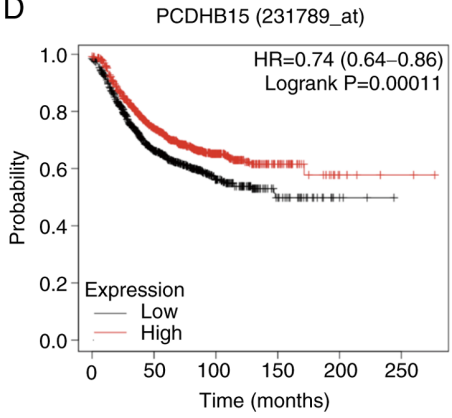

$\mathrm{F}$

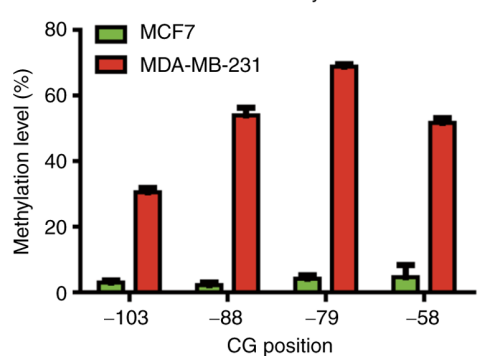

C

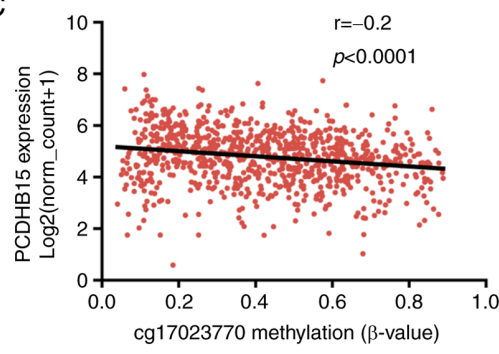

E

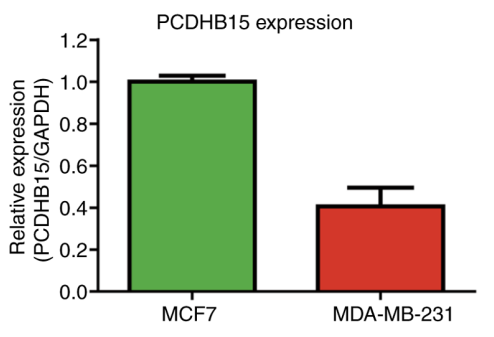

G

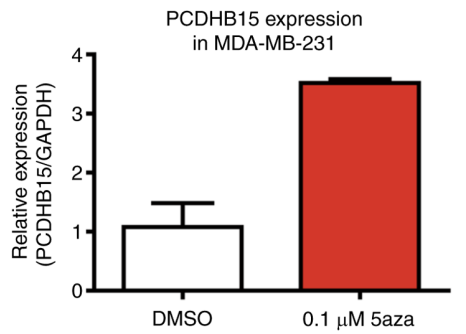

$\mathrm{H}$ PCDHB15 expression
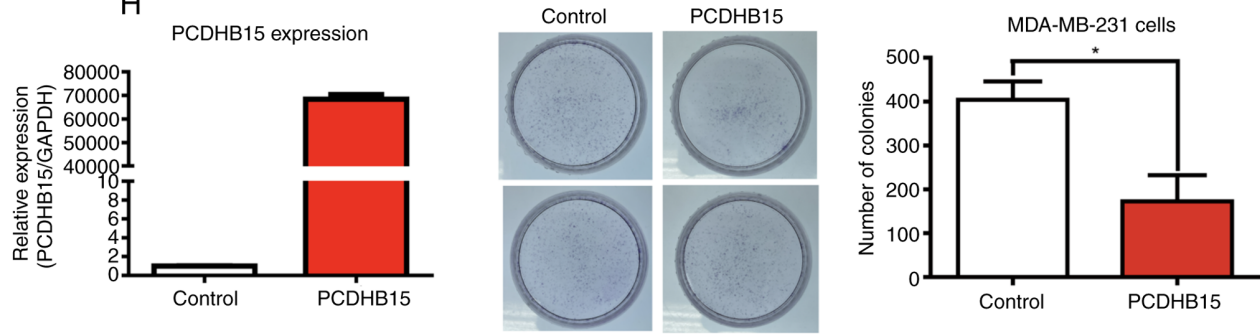

Figure 1. $P C D H B 15$ may be a tumor suppressor gene that is epigenetically silenced in in breast cancer. (A) Schematic diagram depicting the genomic structure and position of the CG sites (vertical dashes) in the $P C D H B 15$ promoter region (from-1,000 to +400 with respect to the transcriptional start site). The location of the microarray probes (red vertical dashes), bisulphite pyrosequencing (yellow horizontal line) and qMSP primers (blue solid arrows) are indicated. (B) DNA methylation level ( $\beta$-value from Illumina Infinium $450 \mathrm{~K}$ microarray) of the PCDHB15 CpG island from-278 (cg03572772) to +2252 (cg15006101) in solid tissue normal (white) vs. primary tumor (red) in TCGA breast cancer dataset. Primary tumor tissues $(\mathrm{n}=785)$ had higher methylation levels than solid tissue normal tissues $(\mathrm{n}=98)$. The $\mathrm{x}$-axis indicates the name of the probe on the microarray. (C) Scatter plot showing correlation between $P C D H B 15$ promoter methylation (cg17023770; $\mathrm{x}$-axis) and expression (y-axis) in TCGA breast cancer dataset $(\mathrm{n}=873)$. A negative association between promoter methylation and expression was observed. (D) Kaplan-Meier analysis of PCDHB15 mRNA expression in tumor tissues for relapse-free survival of patients with breast cancer. Patients with breast cancer with lower $P C D H B 15$ expression demonstrated shorter relapse-free survival times than patients with higher $P C D H B 15$ expression (log-rank test, $\mathrm{P}=0.00011)$. (E) Relative expression level of PCDHB15 mRNA in MCF7 and MDA-MB-231 breast cancer cells. (F) Methylation analysis of $P C D H B 15$ promoter in breast cancer cell lines using bisulphite pyrosequencing. (G) Relative expression level of $P C D H B 15$ in $0.1 \mu \mathrm{M} 5 \mathrm{aza}$-treated MDA-MB-231 breast cancer cells, compared with DMSO control. (H) Ectopic expression of PCDHB15 inhibited tumor proliferation by colony formation assay. MDA-MB-231 breast cancer cells were transfected with empty (control) or PCDHB15 expression vector. Left panel, reverse transcription-quantitative PCR confirmed overexpression of $P C D H B 15$ in MDA-MB-231 cells transiently transfected with PCDHB15 expression vector. Medium panel, MDA-MB-231 breast cancer cells overexpressing $P C D H B 15$ had significantly fewer colonies than the control. Right panel, quantitative analysis of the colony formation assay. Colony formation assay were performed in duplicate and in two independent experiments (mean $\pm \mathrm{SD}$ ). ${ }^{*} \mathrm{P}<0.05$ and ${ }^{* *} \mathrm{P}<0.001$. PCDHB15, protocadherin $\beta 15$; TCGA, The Cancer Genome Atlas; 5aza, 5'-aza-2'-deoxycytidine; qMSP, quantitative methylation-specific PCR. 
A
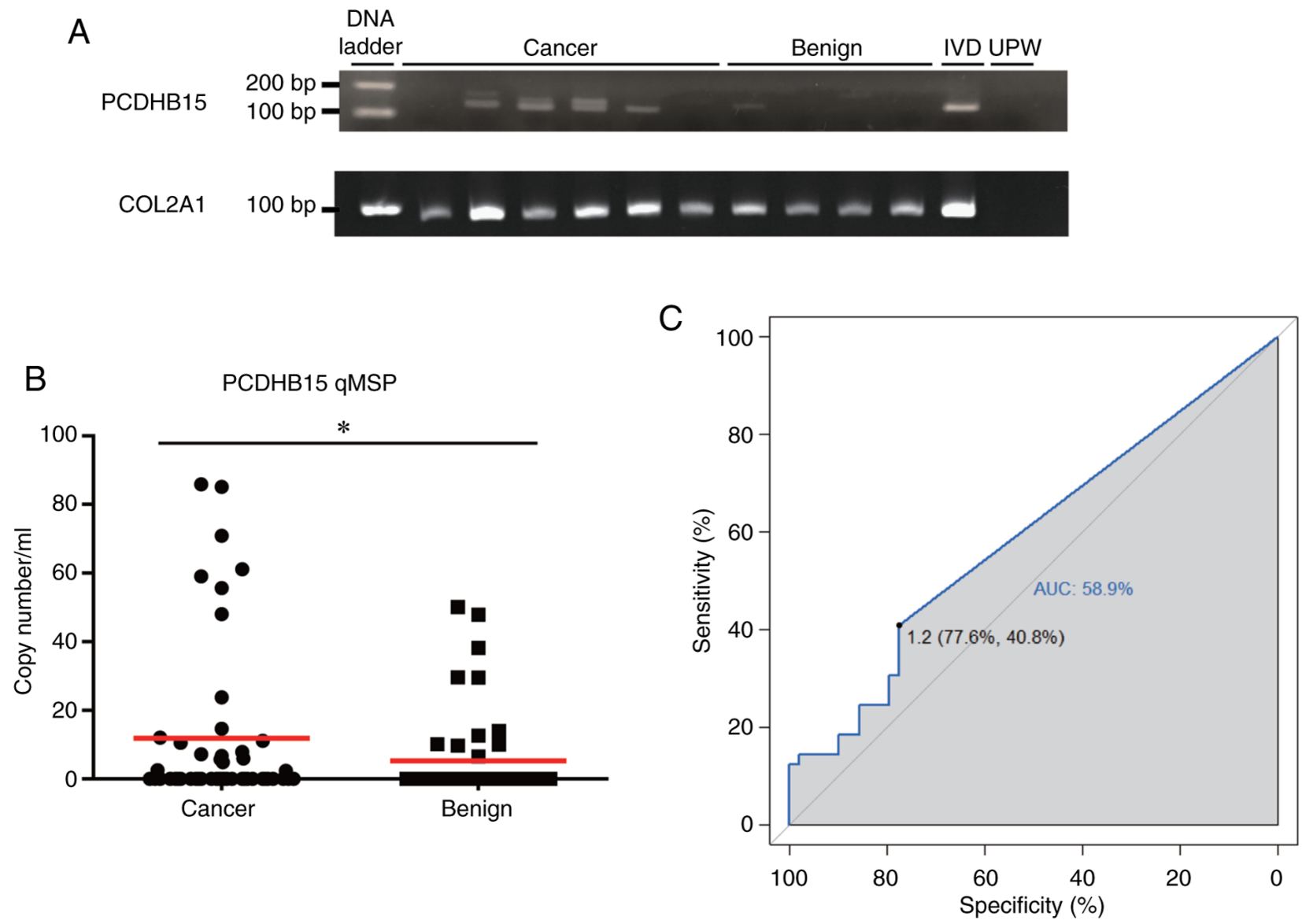

Figure 2. Methylated $P C D H B 15$ level is higher in cfDNA of serum samples of patients with breast cancer. (A) Gel electrophoresis image of $P C D H B 15$ (upper panel) and COL2A1 (lower panel) MSP in cfDNA isolated from serum samples. IVD was a positive control for methylation and $\mathrm{H}_{2} \mathrm{O}$ was a negative control for PCR. (B) qMSP was performed to determine the amount of methylated PCDHB15 in cfDNA of breast cancer (n=49) and benign tumor samples $(\mathrm{n}=49)$. Compared with the benign tumor samples, higher amounts of $P C D H B 15$ were detected in cancer samples. (C) A receiver operating characteristic curve of $P C D H B 15$ methylation in serum samples from 49 patients with breast cancer and 49 patients with benign tumors. The original uncropped gel electrophoresis images can be found in supplementary Fig. S1. * $<0.05$. PCDHB15, protocadherin $\beta 15$; qMSP, quantitative methylation-specific PCR; cfDNA, cell free DNA; IVD, in vitro methylated DNA; AUC, area under the curve; COL21A, collagen type II $\alpha 1$ chain.

in MDA-MB-231 cells led to a significant decrease in the number of colonies, compared with the control vector $(\mathrm{P}<0.05$; Fig. 1H). Taken together, these results suggested that PCDHB15 may be a tumor suppressor subject to epigenetic silencing via promoter hypermethylation in breast cancer.

Measuring PCDHB15 methylation in clinical human serum specimens. The present study also sought to determine whether $P C D H B 15$ methylation could be used as a serum biomarker for breast cancer. MSP revealed $P C D H B 15$ methylation in $66 \%$ (4/6) of cfDNA extracted from serum samples of patients with breast cancer, but only in $25 \%$ of the samples (1/4) from patients with benign tumors (Figs. 2A and S1). The presence of COL2A1 MSP products suggested the presence the cfDNA in serum samples that were devoid of $P C D H B 15$ methylation (Fig. 2A). The $P C D H B 15$ methylation was further examined using qMSP in serum samples from 49 patients with cancer and 49 patients with benign tumors (Table I). The quantity of methylated $P C D H B 15$ was higher in patients with breast cancer than that in samples from patients with benign tumors $(\mathrm{P}<0.05$; Fig. $2 \mathrm{~B})$. Based on the cutoff value generated by the area under the receiver operating characteristic curve (0.589; a cutoff value of 1.2 copy number $/ \mathrm{ml}), P C D H B 15$ methylation in serum samples provided a sensitivity of $40.8 \%$ and specificity of $77.6 \%$ in breast cancer detection (Fig. 2C; Table II). These results demonstrated the feasibility of using $P C D H B 15$ methylation in the cfDNA of serum samples as a minimally invasive biomarker for breast cancer.

PCDHB15 methylation is not correlated with other clinicopathological features. Several proteins, including HER2, $\mathrm{Ki}-67$, estrogen receptor and progesterone receptor, are important parameters in subtyping breast cancer and pathogenesis characterization (6). Nonetheless, our analysis did not reveal any correlation between $P C D H B 15$ methylation and any of those clinical parameters (Fig. 3A-D).

\section{Discussion}

PCDHB15 of the protocadherin superfamily is involved in calcium-dependent cell-cell adhesion. The epigenetic silencing of other cadherins (e.g., E-cadherin) has previously been demonstrated; however, the role of PCDHB15 in breast cancer has yet to be fully understood. In the current 
Table II. Summary of protocadherin $\beta 15$ quantitative methylation-specific PCR analysis.

\begin{tabular}{lcccc}
\hline Diagnosis & Valid specimens (n) & Positive specimens (n) & Negative specimens (n) & Positive rate (\%) \\
\hline Breast cancer & 49 & 20 & 29 & 40.8 \\
Low grade $(\mathrm{G} 1)$ & 4 & 1 & 3 & 25.0 \\
High grade $(\geq \mathrm{G} 2)$ & 37 & 13 & 24 & 35.1 \\
Unknown & 8 & 6 & 2 & 75.0 \\
Benign & 49 & 11 & 38 & 22.4 \\
\hline
\end{tabular}

A

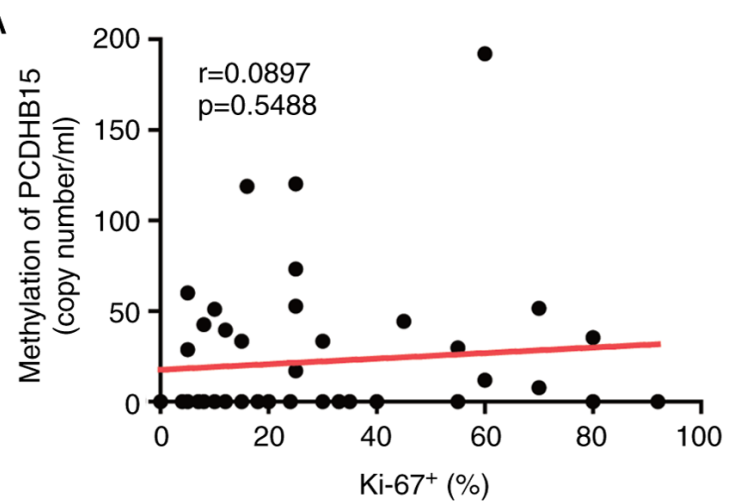

C

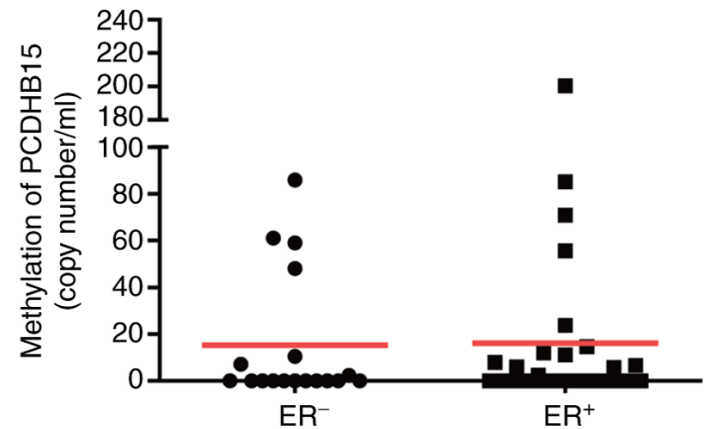

B

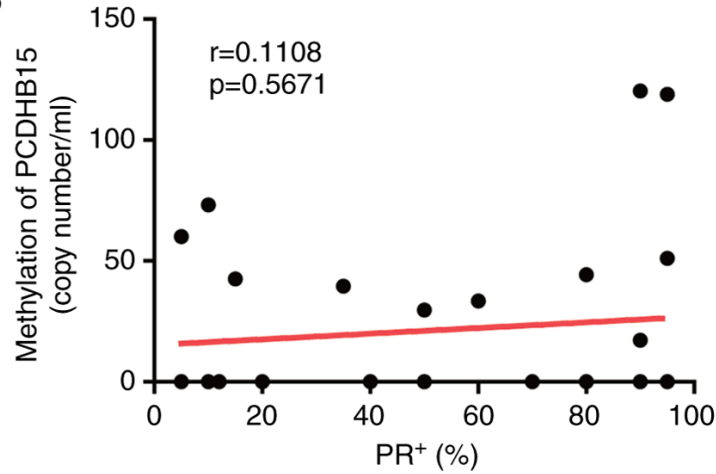

D

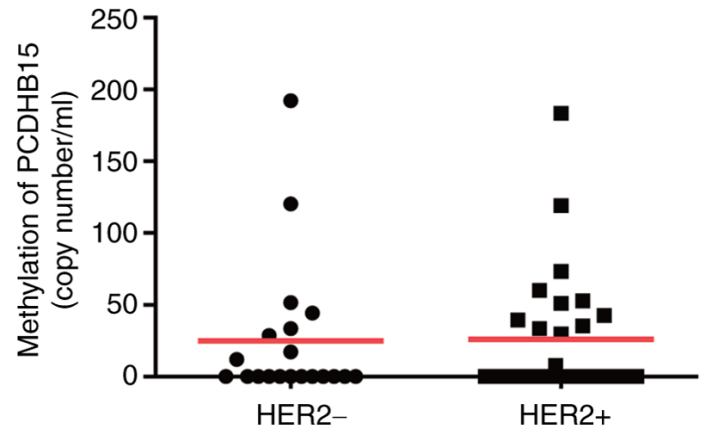

Figure 3. PCDHB15 promoter methylation and the clinicopathological features of breast cancer are not associated. (A and B) Scatter plot showing the correlation between PCDHB15 promoter methylation in cfDNA and expression level of (A) Ki67 and (B) PR in breast tumor tissues. (C and D) Dot plot showing the amount of methylated $P C D H B 15$ in cfDNA with expression status of ER ( $\left.\mathrm{ER}^{+}, \mathrm{ER}^{-}\right)$and $\mathrm{HER}\left(\mathrm{HER}^{+}, \mathrm{HER}^{-}\right)$. PCDHB15, protocadherin $\beta 15$; PR, progesterone receptor; cfDNA, cell free DNA; ER, estrogen receptor; HER2, human epidermal growth factor receptor 2.

study, based on the TCGA database and in-house samples, it was determined that $P C D H B 15$ methylation was more pronounced in patients with breast cancer compared with that in patients with benign tumors or in normal controls. Overall, the higher expression level of $P C D H B 15$ was positively associated with relapse-free survival. Further analysis on specific cell lines revealed that PCDHB15 may be a tumor suppressor downregulated via promoter hypermethylation. It is also noteworthy to point out that the correlation between $P C D H B 15$ methylation and relapse-free survival could not be determined, as DNA methylation data was not available from the Kaplan-Meier Plotter. The prognostic significance of $P C D H B 15$ methylation requires further investigation. It was recently reported that $P C D H B 15$, acting as a tumor suppressor through the inhibition of WNT/ $\beta$-catenin signaling, was epigenetically silenced in KRAS-mutated colorectal cancer (35). This phenomenon can perhaps be attributed to the overexpression of mitochondria glutamate transporter, SLC25A22, in KRAS-mutated colorectal cancer. Nonetheless, determining whether the overexpression of SLC25A22 is responsible for $P C D H B 15$ methylation in breast cancer is worthy of further investigation.

In the present study, $P C D H B 15$ methylation was higher in cfDNA from serum samples of patients with breast cancer than that from patients with benign tumors. Nonetheless, $P C D H B 15$ methylation was not associated with any clinical parameters, thereby suggesting that $P C D H B 15$ methylation may occur early in the carcinogenesis. It also suggested that $P C D H B 15$ methylation is common to all molecular subtypes of breast cancer. The fact that $22.4 \%$ (11 out of 49 ) of the benign tumor samples tested positive for $P C D H B 15$ methylation supports these hypotheses; however, further clinical analysis using a larger sample size and different molecular subtypes will be 
required to demonstrate whether $P C D H B 15$ methylation is involved in the field defect of breast cancer (36).

The sensitivity of $P C D H B 15$ methylation (40.8\%) in breast cancer detection in serum would not allow its use as a sole biomarker; however it could potentially serve as one epigenetic biomarker in a 'methylation signature panel' for the diagnosis and/or prognosis of breast cancer (37-39). Previous studies have identified distinct methylation biomarkers indicating the signaling-mediated epigenetic silencing of tumor suppressors, regardless of different subtypes of breast (40-42). Multiple research groups are currently evaluating the methylation signature panel of GSTP1, RASSF1 and RARB for the detection of breast cancer (29). The PITX2 methylation assay, which has been already certified for in vitro diagnosis, has proven effective as a prognostic and predictive biomarker for breast cancer (43). It is possible that methylation of $P C D H B 15$ could be used in conjunction with these markers to form a novel epigenetic panel by which to characterize the progression of breast cancer.

In conclusion, $P C D H B 15$ is a potential tumor suppressor subject to epigenetic silencing via promoter methylation in breast cancer. $P C D H B 15$ methylation in serum cfDNA may provide a novel minimally invasive epigenetic biomarker for the diagnosis and prognosis of breast cancer. Determining whether $P C D H B 15$ methylation is involved in the early carcinogenesis of breast cancer warrants further investigation.

\section{Acknowledgements}

Not applicable.

\section{Funding}

The present study was supported by grants from the Ministry of Science and Technology, Taiwan (grant no. MOST 108-2314-B-194-003-MY2), the Ditmanson Medical Foundation Chiayi Christian Hospital, Taiwan (grant no. RCN009) and the Center for Innovative Research on Aging Society (grant no. 107-B128-09) from The Featured Areas Research Center Program within the framework of the Higher Education Sprout Project by Ministry of Education in Taiwan.

\section{Availability of data and materials}

The datasets used and/or analyzed during the current study are available from the corresponding author on reasonable request.

\section{Authors' contributions}

CCC, GLL, CWT, CFW and YCH collected patient samples and analyzed clinical data. GLL, WLH, FCW, PJL, WHH, YMC and YTL performed experiments. YMC, SYY and MWYC performed the bioinformatic analysis. GLL, SYY and MWYC wrote the manuscript. CCY, YCH and MWYC designed the experiments. GLL, WLH and MWYC confirm the authenticity of all the raw data. All authors read and approved the final manuscript.

\section{Ethics approval and consent to participate}

The present study was approved (approval no. IRB2019006 on 2019/3/5) by the Institutional Review Board of the Ditmanson Medical Foundation Chiayi Christian Hospital (Chiayi, Taiwan). Written informed consent was obtained from all participants.

\section{Patient consent for publication}

Not applicable.

\section{Competing interests}

The authors declare that they have no competing interests.

\section{References}

1. Liu FC, Lin HT, Kuo CF, See LC, Chiou MJ and Yu HP: Epidemiology and survival outcome of breast cancer in a nationwide study. Oncotarget 8: 16939-16950, 2017.

2. Kuo CN, Liao YM, Kuo LN, Tsai HJ, Chang WC and Yen Y: Cancers in Taiwan: Practical insight from epidemiology, treatments, biomarkers, and cost. J Formos Med Assoc 119: 1731-1741, 2020.

3. Chen YP, Lu YW and Yang CC: Breast cancer trend in Taiwan. MOJ Womens Health 6: 153, 2017.

4. Rossi S, Cinini C, Di Pietro C, Lombardi CP, Crucitti A, Bellantone R andCrucitti F: Diagnostic delay in breast cancer: Correlation with disease stage and prognosis. Tumori 76: 559-562, 1990.

5. Wang R, Li X, Zhang HM, Wang K and He JJ: Cell-free circulating tumor DNA analysis for breast cancer and its clinical utilization as a biomarker. Oncotarget 8: 75742-75755, 2017.

6. Jafari SH, Saadatpour Z, Salmaninejad A, Momeni F, Mokhtari M, Nahand JS, Rahmati M, Mirzaei $\mathrm{H}$ and Kianmehr M: Breast cancer diagnosis: Imaging techniques and biochemical markers. J Cell Physiol 233: 5200-5213, 2018.

7. De Mattos-Arruda L and Caldas C: Cell-free circulating tumour DNA as a liquid biopsy in breast cancer. Mol Oncol 10: 464-474, 2016.

8. Seale KN and Tkaczuk KHR: Circulating biomarkers in breast cancer. Clin Breast Cancer: Sep 22, 2021. doi: 10.1016/j. clbc.2021.09.006 (Epub ahead of print).

9. Schwarzenbach H, Hoon DS and Pantel K: Cell-free nucleic acids as biomarkers in cancer patients. Nat Rev Cancer 11: 426-437, 2011.

10. Potter NT, Hurban P, White MN, Whitlock KD, Lofton-Day CE, Tetzner R, Koenig T, Quigley NB and Weiss G: Validation of a real-time PCR-based qualitative assay for the detection of methylated SEPT9 DNA in human plasma. Clin Chem 60: 1183-1191, 2014.

11. Lamb YN and Dhillon S: Epi proColon ${ }^{\circledR} 2.0 \mathrm{CE}$ : A blood-based screening test for colorectal cancer. Mol Diagn Ther 21: 225-232, 2017.

12. Simon $\mathrm{R}$ and Roychowdhury $\mathrm{S}$ : Implementing personalized cancer genomics in clinical trials. Nat Rev Drug Discov 12: 358-369, 2013.

13. Jones PA, Issa JP and Baylin S: Targeting the cancer epigenome for therapy. Nat Rev Genet 17: 630-641, 2016.

14. Locke WJ, Guanzon D, Ma C, Liew YJ, Duesing KR, Fung KYC and Ross JP: DNA methylation cancer biomarkers: Translation to the clinic. Front Genet 10: 1150, 2019.

15. Lee TL, Leung WK, Chan MW, Ng EK, Tong JH, Lo KW, Chung SC, Sung JJ and To KF: Detection of gene promoter hypermethylation in the tumor and serum of patients with gastric carcinoma. Clin Cancer Res 8: 1761-1766, 2002.

16. Tang Q, Cheng J, Cao X, Surowy $\mathrm{H}$ and Burwinkel B: Blood-based DNA methylation as biomarker for breast cancer: A systematic review. Clin Epigenetics 8: 115, 2016.

17. Wei KL, Chou JL, Chen YC, Low JT, Lin GL, Liu JL, Chang TS, Chen WM, Hsieh YY, Yan PS, et al: Epigenetic silencing of STAT3-targeted miR-193a, by constitutive activation of JAK/STAT signaling, leads to tumor progression through overexpression of YWHAZ in gastric cancer. Front Oncol 11: 575667, 2021. 
18. Fackler MJ, Umbricht CB, Williams D, Argani P, Cruz LA, Merino VF, Teo WW, Zhang Z, Huang P, Visvananthan K, et al: Genome-wide methylation analysis identifies genes specific to breast cancer hormone receptor status and risk of recurrence. Cancer Res 71: 6195-6207, 2011.

19. Fleischer T, Frigessi A, Johnson KC, Edvardsen H, Touleimat N, Klajic J, Riis ML, Haakensen VD, Wärnberg F, Naume B, et al: Genome-wide DNA methylation profiles in progression to in situ and invasive carcinoma of the breast with impact on gene transcription and prognosis. Genome Biol 15: 435, 2014.

20. Jovanovic J, Ronneberg JA, Tost J and Kristensen V: The epigenetics of breast cancer. Mol Oncol 4: 242-254, 2010.

21. Lu J, Wilfred P, Korbie D and Trau M: Regulation of canonical oncogenic signaling pathways in cancer via DNA methylation. Cancers (Basel) 12: 3199, 2020.

22. Tao S, Li H, Ma X, Lian B, He J, Gao Y and Li J: Methylation-mediated silencing of MicroRNA-497 promotes breast cancer progression through up-regulation of Mucin1. Front Oncol 10: 552099, 2020.

23. Zhang C, Zhao H, Li J, Liu H, Wang F, Wei Y, Su J, Zhang D, Liu T and Zhang Y: The identification of specific methylation patterns across different cancers. PLoS One 10: e0120361, 2015.

24. Wu Q and Maniatis T: A striking organization of a large family of human neural cadherin-like cell adhesion genes. Cell 97 779-790, 1999

25. Hulpiau P and van Roy F: Molecular evolution of the cadherin superfamily. Int J Biochem Cell Biol 41: 349-369, 2009.

26. Serrano-Gomez SJ, Maziveyi M and Alahari SK: Regulation of epithelial-mesenchymal transition through epigenetic and post-translational modifications. Mol Cancer 15: 18, 2016.

27. Zou D, Yoon HS, Perez D, Weeks RJ, Guilford P and Humar B: Epigenetic silencing in non-neoplastic epithelia identifies E-cadherin (CDH1) as a target for chemoprevention of lobular neoplasia. J Pathol 218: 265-272, 2009.

28. Asiaf A, Ahmad ST, Aziz SA, Malik AA, Rasool Z, Masood A and Zargar MA: Loss of expression and aberrant methylation of the CDH1 (E-cadherin) gene in breast cancer patients from Kashmir. Asian Pac J Cancer Prev 15: 6397-6403, 2014.

29. de Ruijter TC, van der Heide F, Smits KM, Aarts MJ, van Engeland M and Heijnen VCG: Prognostic DNA methylation markers for hormone receptor breast cancer: A systematic review. Breast Cancer Res 22: 13, 2020.

30. Livak KJ and Schmittgen TD: Analysis of relative gene expression data using real-time quantitative PCR and the 2(-Delta Delta C(T)) method. Methods 25: 402-408, 2001.

31. Chou JL, Huang RL, Shay J, Chen LY, Lin SJ, Yan PS, Chao WT, Lai YH, Lai YL, Chao TK, et al: Hypermethylation of the TGF- $\beta$ target, ABCA1 is associated with poor prognosis in ovarian cancer patients. Clin Epigenetics 7: 1, 2015.

32. Chen PC, Tsai MH, Yip SK, Jou YC, Ng CF, Chen Y, Wang X, Huang W, Tung CL, Chen GC, et al: Distinct DNA methylation epigenotypes in bladder cancer from different Chinese sub-population and its implication in cancer detection using voided urine. BMC Med Genomics 4: 45, 2011.
33. Tseng KC, Chou JL, Huang HB, Tseng CW, Wu SF and Chan MW: SOCS-1 promoter methylation and treatment response in chronic hepatitis $\mathrm{C}$ patients receiving pegylated-interferon/ribavirin. J Clin Immunol 33: 1110-1116, 2013.

34. Györffy B, Lanczky A, Eklund AC, Denkert C, Budczies J, Li Q and Szallasi Z: An online survival analysis tool to rapidly assess the effect of 22,277 genes on breast cancer prognosis using microarray data of 1,809 patients. Breast Cancer Res Treat 123: 725-731, 2010.

35. Wong CC, Xu J, Bian X, Wu JL, Kang W, Qian Y, Li W, Chen H, Gou H, Liu D, et al: In colorectal cancer cells with mutant KRAS, SLC25A22-mediated glutaminolysis reduces DNA demethylation to increase WNT signaling, stemness, and drug resistance. Gastroenterology 159: 2163-2180.e6, 2020.

36. Teschendorff AE, Gao Y, Jones A, Ruebner M, Beckmann MW, Wachter DL, Fasching PA and Widschwendter M: DNA methylation outliers in normal breast tissue identify field defects that are enriched in cancer. Nat Commun 7: 10478, 2016.

37. Du T, Liu B, Wang Z, Wan X and Wu Y: CpG methylation signature predicts prognosis in breast cancer. Breast Cancer Res Treat 178: 565-572, 2019.

38. Peng Y, Shui L, Xie J and Liu S: Development and validation of a novel 15-CpG-based signature for predicting prognosis in triple-negative breast cancer. J Cell Mol Med 24: 9378-9387, 2020.

39. Mao XH, Ye Q, Zhang GB, Jiang JY, Zhao HY, Shao YF, Ye ZQ, Xuan ZX and Huang P: Identification of differentially methylated genes as diagnostic and prognostic biomarkers of breast cancer. World J Surg Oncol 19: 29, 2021.

40. Chou JL, Chen LY, Lai HC and Chan MW: TGF- $\beta$ : Friend or foe? The role of TGF- $3 /$ SMAD signaling in epigenetic silencing of ovarian cancer and its implication in epigenetic therapy. Expert Opin Ther Targets 14: 1213-1223, 2010.

41. Bloushtain-Qimron N, Yao J, Snyder EL, Shipitsin M, Campbell LL, Mani SA, Hu M and Chen H: Cell type-specific DNA methylation patterns in the human breast. Proc Natl Acad Sci USA 105: 14076-14081, 2008.

42. Novak P, Stampfer MR, Munoz-Rodriguez JL, Garbe JC, Ehrich M, Futscher BW and Jensen TJ: Cell-type specific DNA methylation patterns define human breast cellular identity. PLOS One 7: e52299, 2012.

43. Beltran-Garcia J, Osca-Verdegal R, Mena-Molla S and Garcia-Gimenez JL: Epigenetic IVD tests for personalized precision medicine in cancer. Front Genet 10: 621, 2019.

(i) $\odot$ This work is licensed under a Creative Commons Attribution-NonCommercial-NoDerivatives 4.0 International (CC BY-NC-ND 4.0) License. 